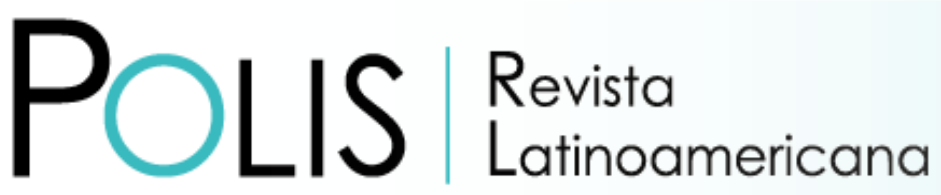

V20 | N58 | 2021

DOI: $10.32735 /$ S0718-6568/2021-N58-1582

\title{
Política energética, regalías hidrocarburíferas y extractivismo en las provincias argentinas. El caso de Vaca Muerta (2011-2019)
}

\author{
María Paula Lucero \\ Maestrando en Ambiente y Desarrollo Sustentable, Universidad Nacional de Quilmes, \\ Buenos Aires, Argentina. \\ Email: mpaulalucero94@gmail.com
}

Recibido: 04.03.2020 | Aceptado: 17.06.2020

\begin{abstract}
Resumen: El presente trabajo analiza los factores que intervienen en la decisión de cuatro provincias argentinas (La Pampa, Mendoza, Neuquén, Rio Negro) de aceptar e impulsar el proyecto de extracción de hidrocarburos convencionales en la formación Vaca Muerta. Articulando la literatura sociológica, económica y de política ambiental sobre fracking, se analiza la incidencia de las variables allí propuestas, prestando especial atención a la influencia del rol del Estado, el comportamiento de los actores políticos locales y el sistema de regalías, mediante la utilización de una metodología mixta (relevamiento de datos cuantitativos, normativas, discursos, informes de gestión, etc.). Se concluye que los factores que explican el desarrollo de proyectos de fracking son heterogéneos y multicausales, por lo que resulta relevante analizar las dinámicas propios de cada provincia.
\end{abstract}

Palabras clave: Política energética; extractivismo; fracking; regalías hidrocarburíferas.

\section{Energy Policy, Hhydrocarbon Royalties and Extractivism in the Argentine Provinces. The Case of Vaca Muerta, Argentina (2011 hidrocarbonetos -2019)}

\begin{abstract}
The article analyzes the factors that intervene in the decision of four Argentine provinces (La Pampa, Mendoza, Neuquén, Rio Negro) to accept and promote the hydrocarbon extraction project in the Vaca Muerta formation. Articulating the sociological, economic and environmental policy literature about fracking, the article analyzes the incidence of key variables paying special attention to the influence and role of state behavior, political actors and the system of royalties through the use of mixed methodology (quantitative data survey, normative, speeches, management reports). It concludes that the factors that explain the development of fracking projects are heterogeneous and multi-causal therefore, it is relevant to analyze the dynamics of each province.
\end{abstract}

Keywords: Energy policy; extractivism; fracking; hydrocarbon royalties. 


\section{Estado, royalties de e extrativismo nas províncias argentinas. O caso de Vaca Muerta, Argentina (2011-2019)}

Resumo: $O$ presente artigo analisa os fatores envolvidos na decisão de quatro províncias argentinas (La Pampa, Mendoza, Neuquén, Rio Negro) de aceitar e promover o projeto de extração de hidrocarbonetos convencionais na formação de Vaca Muerta. Articulando a literatura sociológica, econômica e de política ambiental sobre fracking, é analisada a incidência das variáveis propostas, prestando especial atenção à influência do papel do Estado, do comportamento dos atores políticos locais e do sistema de royalties, através do uso de uma metodologia mista (coleta quantitativa de dados, regulamentos, discursos, relatórios gerenciais, etc.). Conclui-se que os fatores que explicam o desenvolvimento de projetos de fracking são heterogêneos e multicausais, por isso que é relevante analisar as dinâmicas próprias de cada província.

Palavras-chave: Política energética; extrativismo; fracking; royalties de hidrocarbonetos.

\section{Como citar este artículo:}

Lucero, M. (2021). Política energética, regalías hidrocarburíferas y extractivismo en las provincias argentinas. El caso de Vaca Muerta (2011-2019). Polis Revista Latinoamericana, 20 (58), 141-159. doi: http://dx.doi.org/10.32735/S0718-6568/2021-N58-1582

\section{Introducción}

La energía es un elemento central a la hora de pensar el desarrollo productivo, económico y social de un país. Como afirman Morina y Cacace (2014, p. 49) "la cuestión energética no es sólo una cuestión técnica, sino fundamentalmente política, económica, social y ambiental". La matriz energética argentina presenta una alta dependencia (alrededor del 90\%) de combustibles fósiles (gas, petróleo y carbón), recursos naturales energéticos no renovables y cada vez más escasos. En la última década, en un escenario caracterizado por déficit energético y progresivo agotamiento de hidrocarburos' convencionales, los gobiernos de la región se orientaron a buscar nuevos yacimientos de hidrocarburos no convencionales (en adelante $\mathrm{HCNC}$ ), denominados así debido a que son reservas de petróleo y gas de baja permeabilidad que, por factores geológicos, no pueden ser extraídos por métodos tradicionales y para cuya extracción se requieren nuevos métodos, como la técnica de fractura hidráulica, o fracking ${ }^{2}$ (D'Elía y Ochandio, 2014).

El yacimiento Vaca Muerta es la formación sedimentaria (o roca madre) que posee la mayor cantidad de reservorio no convencional en el país y buena parte de la región, siendo la segunda reserva mundial de gas y la cuarta reserva de petróleo, cuya condición geofísica (localizado a más de 3.000 metros de profundidad) condiciona su extracción, siendo la perforación horizontal y la fractura hidráulica los únicos procedimientos de extracción posibles

\footnotetext{
1 Los hidrocarburos comprenden a los compuestos orgánicos formados por átomos de carbono e hidrógeno. 2 Se entiende por fractura hidráulica o fracking a la técnica que consiste en inyectar agua, arena silícea, y productos químicos a las formaciones rocosas con el fin de extraer los hidrocarburos (gas, petróleo) que se encuentran atrapados en las rocas. Se la considera una "técnica experimental" debido a la imposibilidad de controlar el alcance y recorrido de las fracturas a pesar del monitoreo a cargo de las empresas, lo que puede generar derrames (D'Elía y Ochandio, 2014).
} 
(D'Elia y Ochandio, 2014). Desde su exploración ha generado transformaciones en el territorio, tanto económicas, por las grandes inversiones de capital extranjero, como sociales, debido a las tensiones que provoca entre quienes defienden y quienes se oponen al desarrollo del megaproyecto. Ello en un contexto de multiplicación en América Latina de conflictos socioambientales en oposición al desarrollo de proyectos extractivos de explotación de recursos naturales no renovables (megaminería, fracking, agronegocios, etc.) para satisfacer la creciente demanda internacional de gas, petróleo y energía (Rodríguez Garavito, 2016).

Desde el marco legal, existen países en los que el fracking, en un escenario marcado por cuestionamientos sociales y luchas ambientales, se encuentra prohibido/suspendido, ya sea en todo el territorio nacional (Francia, Bulgaria, Holanda, Alemania, Irlanda, Uruguay) o en ciertos Estados locales (Vermond, New York y Maryland en Estados Unidos, Paraná en Brasil, Quebec en Canadá, Victoria en Australia). En Argentina, Entre Ríos se convirtió en 2017 en la primera provincia ${ }^{3}$ en prohibir la extracción de hidrocarburos mediante la fractura hidráulica (ley 10.477). A su vez, a nivel local, municipios que poseen recursos no convencionales sancionaron legislaciones que prohíben su explotación mediante fracking, incluso en algunas de las provincias que conforman Vaca Muerta. Ello no exento de conflictos entre la población local y los gobernadores, quienes en ocasiones han intentado derogar las normativas acusando la inconstitucionalidad de los municipios de legislar en la materia, generándose así una tensión entre las normativas nacionales y provinciales de incentivo y garantía a la explotación de HCNC y las demandas a nivel provincial y local/municipal de legislaciones que prohíban el fracking.

Las provincias que forman parte del yacimiento Vaca Muerta (La Pampa, Mendoza, Neuquén y Rio Negro) presentan características sociales, económicas y políticas diversas. Sin embargo, las cuatro impulsaron el megaproyecto hidrocarburífero. En base a ello, el siguiente trabajo se orienta a indagar sobre cuáles son los factores que intervienen en la decisión de explotar proyectos de hidrocarburos, mediante la técnica del fracking en Estados federales descentralizados en los cuales los gobiernos subnacionales deciden sobre los recursos naturales en sus territorios. Ello, prestando especial atención a las características de cada provincia, el rol del Estado y las características que presenta el federalismo fiscal. Se argumenta aquí que los factores que inciden en su desarrollo son la voluntad política del Estado nacional y las características del sistema de transferencias fiscales, en lo que respecta a las regalías hidrocarburíferas.

El trabajo se estructura en cinco apartados, seguido de esta introducción, se presenta el escenario de políticas públicas orientadas a energía e hidrocarburos durante el segundo mandato de Cristina Fernández de Kirchner (2011-2015) y el gobierno de Mauricio Macri (2015-2019). A continuación, se analiza los factores que, según la literatura de las ciencias sociales orientada al estudio de los hidrocarburos y el fracking, intervienen a la hora de impulsar actividades extractivas. Se observan las tensiones y asimetrías sociales que se generan en el territorio, el marco legal, el sistema de regalías y transferencias fiscales, entre

3 Se entiende por provincias a la división administrativa territorial en que se organiza el Estado argentino. 
otros. Luego, se presenta la metodología utilizada y se analizan los casos bajo estudio a la luz de los factores extraídos de la literatura. Por último, se retoman las principales ideas y las conclusiones que se desprenden del presente trabajo.

\section{Política energética e hidrocarburífera (2011-2019)}

La política energética, como afirman Recalde, Bouille y Girardin (2015, p. 93) tanto en su diseño como en su implementación se encuentra condicionada por una multiplicidad de factores (contexto, marcos regulatorios, políticos e institucionales, etc.) que determinan las barreras, actores e instrumentos que intervienen y modifican su resultado final. A continuación, se analiza la política energética argentina durante la última década.

El segundo mandato de Cristina Fernández de Kirchner (2011-2015) se caracteriza por una política energética orientada a dar respuesta al desabastecimiento energético mediante el impulso a la explotación de HCNC. La expropiación por parte del Estado Nacional del $51 \%$ de las acciones de YPF al grupo Repsol (España) en 2012 mediante la "Ley de Soberanía Hidrocarburífera" (26.741/2012) consolidó la política energética del gobierno. Dicha ley declara al autoabastecimiento de hidrocarburos "de interés público nacional y como objetivo prioritario de la República Argentina" siendo el Poder Ejecutivo nacional la principal autoridad y árbitro del cumplimiento de la política hidrocarburífera en el nivel subnacional (art.2) y habilita la explotación de hidrocarburos mediante la técnica de fracking al sancionar "la incorporación de nuevas tecnologías y modalidades de gestión que contribuyan al mejoramiento de las actividades de exploración y explotación de hidrocarburos" (art. 3). Si bien existían provincias históricamente dedicadas a la actividad petrolera, la ley reglamenta el fracking como una nueva modalidad de explotación.

Así, ante la crisis energética, la explotación de yacimientos no convencionales se presentó como una forma de dar respuesta al déficit producido por el aumento de la demanda de consumo de energía y la caída en la extracción convencional. Ello fue posibilitado por transformaciones en el marco normativo, tales como el "Régimen de Soberanía Hidrocarburífera de la República Argentina" (decreto 1277/12), el "Nuevo Régimen de Soberanía Hidrocarburífera", la creación de un "Plan Nacional de Inversiones Hidrocarburíferas", y el Decreto 929/2013 que otorga garantías de inversión, beneficios fiscales y económicos a las empresas a fin de estimular a los capitales privados. El acuerdo YPF S.A- Chevron- Neuquén en 2013 y el Plan Estratégico de YPF 2013-2017, luego del descubrimiento por parte de Repsol-YPF de 4,5 millones de metros cúbicos de gas no convencional y de la divulgación del informe de la Agencia de Información Energética de Estados Unidos (EIA) que incluye a la formación Vaca Muerta entre los yacimientos con mayor reserva a nivel mundial de HCNC (shale oil y tight gas), pueden ser leídos como una bisagra que habilita el ingreso del fracking a las provincias argentinas (Observatorio Petrolero Sur, 2011; D'Elia y

4 YPF (Yacimientos Petrolíferos Fiscales) es la empresa argentina de energía dedicada a la exploración, explotación, distribución y producción de hidrocarburos y derivados de gran significancia simbólica, la cual, durante los años 1998 y 199, fue privatizada y transformada en una Sociedad Anónima con escasa participación del Estado. 
Observatorio Petrolero Sur, 2014) Dicho informe fue tenido en cuenta por el Ejecutivo nacional en el discurso de expropiación de YPF: "somos el tercer país en el mundo, tal cual lo dice la agencia, la propia agencia de petróleo y energía de Estados Unidos, luego de China y Estados Unidos en tener gas Shale de reciente descubrimiento" (Fernández, 2012).

Así, con el apoyo del gobierno nacional y gobernadores provinciales, se instalaron los primeros proyectos de explotación de hidrocarburos, principalmente en las provincias patagónicas (Neuquén, Chubut, Santa Cruz, Rio Negro), como lo evidencia el Plan Gas, creado en 2013 , que consistía en un subsidio al precio de la boca de pozo para incentivar la producción de gas natural por parte de privados. Al mismo tiempo, comenzaron a ampliarse las fronteras hacia zonas sin trayectoria en hidrocarburos, como Entre Ríos (Acuífero Guaraní) y Buenos Aires (Claromecó y Tandil), lo que fue posible por la reglamentación de nuevas tecnologías de explotación.

A nivel subnacional, el contexto en el que se aprueba la expropiación de las acciones de YPF se caracteriza por la presencia de tensiones sociales, luego de la visibilización a nivel nacional de la conflictividad social surgida a nivel local puesta de manifiesto en la pueblada en Famatina (La Rioja) en oposición a la megaminería (Svampa y Viale, 2014). Lo mismo sucedía en torno al fracking, al tiempo que comenzaban los proyectos de explotación se intensificaba la oposición a este tipo de actividad extractivista. Así, aumentaron las resistencias y manifestaciones en diferentes provincias argentinas, que tenían como protagonistas a movimientos socioambientales, pueblos originarios, asambleas de vecinos autoconvocados, multisectoriales, entre otros, que incidieron en la sanción de la primera legislación que prohíbe el fracking en el municipio Cinco Saltos 5 , Rio Negro, convirtiéndose en el primer municipio de América Latina en prohibirlo.

En continuidad con el marco regulatorio energético e hidrocarburífero ya reglamentado, en el 2014 el Estado Nacional con la Organización Federal de Estados Productores de Hidrocarburos (OFEPHI), luego del acuerdo YPF-Chevron, sanciona la "Ley de Hidrocarburos" (27.007/2014), que modifica a la ley 17.319, sancionada en 1967, durante la dictadura cívicomilitar. En la misma utiliza el término "explotación no convencional de hidrocarburos" (art.27 bis), en referencia a aquellos yacimientos de baja permeabilidad, para cuya explotación se establecen concesiones de exportación a capitales privados de hasta treinta y cinco años (pudiendo solicitar una prórroga de 10 años), con un pago de regalías del 12\%, y se prohíbe a las provincias la posibilidad de reservar áreas para ser explotadas por empresas públicas o con participación estatal. En concordancia con el Decreto 929 de 2013, se establece el Régimen de Promoción de las Inversiones para la Explotación de Hidrocarburos (art.19) que otorga garantías jurídicas y fiscales a los capitales privados.

5 La ley fue redactada e impulsada por el concejal José Chandia (PC) en conjunto con vecinos y organizaciones ambientalistas, y aprobada por unanimidad, luego fue vetada por la intendenta con el respaldo del gobierno nacional y provincial debido a, según argumentaron, resultar contraria a la política nacional y la incapacidad legal de los gobiernos locales/municipales de legislar sobre los recursos naturales. No obstante, el veto no se efectivizo por ser "extemporáneo" (La política online, 2013). 
En cuanto a la diversificación energética, las políticas y leyes orientadas a impulsar el desarrollo de energías renovables (eólica, térmica, geotérmica, solar, mareomotriz, etc.) fueron escasas. No obstante, se llevaron a cabo ciertos programas y planes orientados a su promoción, tales como el Proyecto para la promoción de la energía derivada de biomasa (PROBIOMOSA), la Resolución S.E. 108/2011 de contratos para el fomento del abastecimiento energético a partir de fuentes renovables, y el Régimen de Fomento Nacional para el uso de Fuentes Renovables de Energías destinada a la Producción de Energía Eléctrica (ley 27.191), sancionado en octubre de 2015. Sin embargo, la política de energías renovables no logro desarrollarse, principalmente debido a la falta de incentivo e inversión (Recalde et al., 2015).

El gobierno de Mauricio Macri (2015-2019) se caracteriza por una disminución de la intervención del Estado nacional en la regulación, inversión y planificación de la política energética. En esos años, se da una transferencia de recursos hacia las empresas energéticas mediante el aumento de tarifas a los consumidores, y el otorgamiento de permisos de exploración y explotación a capitales privados (García Zanotti, Kofman y Crespo, 2016; Acacio 2018; Acacio y Wyczykier, 2020). En cuanto a subsidios, en comparación entre 2015 y 2019 se evidencia una disminución de subsidios destinados a electricidad ( $1.8 \%$ a $0.9 \%$ ), gas (0.9\% a 0.5\%) y petróleo e hidrocarburos (de 3\% a 1.4\%) (Secretaria de energía, 2019). Una de las primeras medidas impulsadas por el gobierno nacional en materia de hidrocarburos fue el Decreto 272/2015 que disuelve la Comisión de planificación y coordinación estratégica del Plan Nacional de Inversiones Hidrocarburíferas, y establece la autoridad de las provincias para la toma de decisiones en materia hidrocarburífera en sus territorios (Freier y Schaj, 2016).

En cuanto a políticas orientadas a lograr la diversificación energética, a comienzos del 2016 el gobierno reglamentó la ley 27.191/2015, sancionada por el anterior gobierno, que establece como objetivo prioritario lograr una contribución de las fuentes de energía renovables mediante incentivos a las empresas (impuesto al valor agregado, bienes amortizables, infraestructura, etc.) con el fin de alcanzar el ocho por ciento del consumo de energía eléctrica nacional en diciembre de 2017 (art.2) y un veinte por ciento en 2025. En la misma línea, el Programa Renovar (136/2016), realizado en conjunto con Compañía Administradora del Mercado Mayorista Eléctrico (CAMMESA) adjudicó contratos de abastecimiento de energía eléctrica renovable. Según la Secretaría de Energía (2019), existen a la fecha 155 proyectos en operación (60) y producción (95) de energía renovables.

Sin embargo, en paralelo a la política de fomento de renovables, el gobierno impulsó la explotación de HCNC a través de incentivos legales, garantías, planes de inversión y subsidios. A principios de 2017 el gobierno firmó el Acuerdo Vaca Muerta con los gobernadores de Rio Negro, La Pampa y Neuquén, y las empresas YPF, Pan American Energy y Total Austral. En su anuncio, el presidente Mauricio Macri (Macri, 2017) afirmaba: "Este es un acuerdo histórico por lo que significa la energía (...) el elemento fundamental para poder desarrollarnos (...) queremos emprender del desarrollo de nuestra energía no convencional". Ello fue acompañado por resoluciones y reglamentaciones que incentivaban la explotación de 
gas natural en reservorios no convencionales del yacimiento Vaca Muerta como da cuenta el "Programa de estímulo a las inversiones en desarrollos de producción de gas natural proveniente de reservorios no convencionales - Cuenca Neuquina" (resolución 46/2017), que concede infraestructura, logística y la disminución de la carga tributaria, entre otros beneficios otorgados por el gobierno nacional y provincial de Neuquén. Respecto a los beneficios a las empresas, el presidente afirmaba: "el compromiso de Vaca Muerta empieza por casa (...) teníamos que dar garantías, certidumbres, para que vengan las inversiones, y por eso (...) no se van a seguir aplicando retenciones a la exportación" (Macri, 2017).

Además de sancionar la continuidad del Plan Gas para Vaca Muerta y otras formaciones no convencionales en la Cuenca Neuquina (García Zanotti et al., 2016) y la reglamentación de nuevos convenios colectivos de trabajo del sector petrolero, que implicaron una baja de "costos" para las empresas y pérdida de beneficios para los trabajadores (Acacio y Wyczykier, 2020).

En suma, desde la reglamentación de la explotación de hidrocarburos mediante "la incorporación de nuevas tecnologías" se consolidó el fracking en el país, con grandes incentivos económicos, fiscales y legales a la explotación en detrimento de la ampliación y diversificación de la matriz mediante energías renovables, las cuales, si bien durante los últimos años tuvieron un impulso, el mismo nunca fue superior al otorgado a los hidrocarburos. En ambos gobiernos puede observarse continuidad en la política energética respecto al desarrollo y explotación de no convencionales, aunque con marcadas diferencias. El gobierno de Cristina Fernández se caracteriza por la nacionalización de la política energética en la cual, el Estado tiene un rol central como garante y árbitro tanto del capital privado como de la política energética subnacional, a diferencia del mandato de Mauricio Macri en el que el Estado tiene un rol considerablemente menor, se descentraliza la política y las provincias vuelven a ocupar un lugar central. Así, las distintas políticas tomadas por ambos gobiernos se orientaron a incentivar la llegada de capitales privados para el desarrollo de diversos proyectos de explotación, en los que Vaca Muerta se destaca como la figura central, en torno a la cual se forman posturas y discursos contrapuestos. Por un lado, desde el Estado nacional, provincial y los capitales privados quienes presentan a Vaca Muerta como la solución a los problemas de autoabastecimiento energético y un factor de desarrollo. Por otro lado, vecinos, comunidades de pueblos originarios y organizaciones ambientales, quienes se oponen al fracking y buscan su prohibición.

\section{Fracking, desarrollo, y políticas públicas: Factores intervinientes}

A partir de la literatura sobre los elementos que inciden en el desarrollo y explotación de hidrocarburos no convencionales mediante la técnica de fracking, se presenta a continuación un reducido estado de la cuestión que intenta indagar sobre sus factores explicativos. Así en base a dicha literatura, y con fines analíticos, se clasifican los factores intervinientes en cuatro categorías: estatal, jurídica, territorial y fiscal. 
El factor estatal, da cuenta del rol que presenta la autonomía e independencia del Estado en la reglamentación, regulación y/o prohibición de emprendimientos hidrocarburíferos. Dicha autonomía, entendida como la capacidad de llevar a delante su propia agenda, dependerá de ciertos condicionantes, principalmente su grado de fortaleza/debilidad institucional y económica ante los actores privados transnacionales (Vargas Suárez, 2015), siendo los Estados menos autónomos los que mayor dificultad presentarían para imponer sus reglas y rechazar la imposición de intereses externos. Ello debido a que según argumentan Gutiérrez Ríos (2014) y Giuliani (2017) la política energética e hidrocarburífera es producto de decisiones tomadas entre el Estado, actores públicos y privados, en la medida en que es el Estado quien cuenta con los poderes políticos necesarios para permitir (o no) el desarrollo de proyectos extractivos. Así, la voluntad política y la autonomía que el Estado presente sería un factor determinante.

En Argentina, desde la década del noventa el Estado ha disminuido su rol en política hidrocarburífera al control y fiscalización. Según argumenta Gutiérrez Ríos (2014) con la emergencia del neoliberalismo se consolidó un "Estado empresario", denominado así por su imbricación con actores empresariales, que condiciona al Estado haciéndolo actuar en base a demandas tanto públicas/sociales como privadas/corporativas.

En cuanto al factor jurídico, este refiere a la influencia que el marco legal tiene en el desarrollo de emprendimientos hidrocarburíferos. En ese sentido, Svampa y Viale $(2014$, p. 324) argumentan que el marco legal responde ante el avance de proyectos de explotación hidrocarburífera favoreciendo su desarrollo y limitando la sanción de legislaciones que regulen/prohíban la actividad, como consecuencia del realineamiento entre los distintos poderes del Estado (político, económico y judicial) en favor del fracking. Así, el factor jurídico se encontraría relacionado con el factor estatal en la medida en que, como argumentan los autores, el Estado tiene un rol central en el establecimiento de los marcos legales y jurídicos. En aquellos territorios con conflictividad social en torno al fracking, Rodríguez Garavito (2012) afirma que el marco legal, denominado por el autor como campo socio jurídico entra en tensión entre los distintos actores intervinientes que disputan sus intereses en dicho campo. Esa tensión socio-jurídica se manifiesta en mayor medida en el nivel local, dado que es allí donde emergen los conflictos socioambientales y han tenido mayor éxito para sancionar legislaciones de prohibición ${ }^{6}$.

Respecto al factor de territorialización, por el mismo se entiende a las diversas transformaciones (sociales, económicas, ambientales, infraestructurales, etc. ${ }^{7}$ ) producidas en el territorio en el que se desarrollan los proyectos de explotación de HCNC, que dinamizan y reestructuran las características propias del lugar. Según afirman Freier y Schaj

6 En Argentina existen alrededor de setenta municipios que cuentan con recursos no convencionales y aun así han lograron sancionar ordenanzas que prohíben su explotación, luego de intensas movilizaciones promovidas por la sociedad civil, organizaciones ambientalistas, agrupaciones y partidos políticos (Foro Ambiental, 2017).

7 Como la profundización de estereotipos de división sexual del trabajo, o como lo denomina Svampa "la reactualización del patriarcado en contextos de enclaves", agravados por la percepción social sobre el trabajo petrolero. 
(2016, p.75) estas transformaciones, denominadas como procesos de reterritorializacion (o deterritorialización) aumentan la importancia del gobierno local convirtiéndolo en una esfera gubernamental muy importante en las negociaciones internacionales.

En Argentina las políticas adoptadas por el Estado fueron acompañada por intensas movilizaciones en oposición, ante las cuales el gobierno nacional llevó adelante una "estrategia de provincialización" tendiente a circunscribir las luchas y problemáticas ambientales en el nivel subnacional (Saguier y Peinado, 2014). Ello contribuyó a generar una conflictividad en el espacio donde se dan los emprendimientos, debido a las relaciones de poder desiguales entre empresas y comunidades locales, y la escasa presencia del Estado (Rodríguez Garavito 2016, p. 19). En cuanto a las transformaciones económicas, como afirma Giuliani (2017, p. 54) la alta rentabilidad financiera que genera el fracking incide de forma negativa al disminuir el dinamismo de otros sectores productivo, y ello a su vez, repercute en las condiciones sociales.

El factor fiscal se centra en el estudio de las regalías hidrocarburíferas. Las mismas, pueden ser definidas de diferentes formas: como un derecho adquirido (Tapia, 2014), como una compensación pagadas al Estado por el agotamiento del recurso y las consecuencias que su explotación genera, o como impuestos por ser prestaciones de un particular a favor del Estado (Peralta, Abella y Albareque, 2005).

Como afirman Vergara, Barreto y Prieto Bustos (2012), uno de los aspectos más importantes de las regalías tiene que ver con su eficacia entendiéndose por ello al uso, alcance y cobertura de dichos recursos en provincias y municipios. Sin embargo, según diversos autores (Benavides et al., 2000; Perry y Olivera, 2010, citados en Vergara et al., 2012, p. 17) las regalías no resultan positivas para el desarrollo provincial dado que su distribución carece de políticas y reglas sobre su destino e inversión. Así, el sistema de regalías puede incidir en las condiciones y características que adopten aquellas provincias en las que se desarrollen los proyectos hidrocarburíferos, pudiendo en ocasiones, como argumentan García Delgado (2014) y Tapia (2014), limitar el desarrollo local de las provincias y municipios beneficiados, en la medida en que estas provincias se encuentran más orientadas a impulsar el desarrollo de actividades extractivas por la rentabilidad de ganancia que obtienen a través de las regalías.

Existen ciertos elementos que caracterizan al federalismo fiscal argentino y contribuyen a explicar la tensión existente entre el Estado nacional y subnacional, como la división entre dominio y jurisdicción (Hidalgo, 2009; Peralta et al., 2005) ${ }^{8}$ consagrado en la Constitución Nacional, y el sistema de recaudación de impuestos concentrado en Nación, con una cada vez mayor descentralización de los gastos en el nivel subnacional. Ello, sumado a la desigual capacidad de recaudación de las provincias producto del desequilibrio fiscal vertical existente, que es resuelto por transferencias fiscales discrecionales de recursos recau-

8 Según argumentan los autores, la diferencia existente entre dominio y jurisdicción intensifica las tensiones entre Nación y provincias dado que, mientras las provincias tienen el dominio de sus recursos, es decir, la titularidad del derecho de propiedad sobre los mismos, Nación posee la jurisdicción, la autoridad para dictar leyes/normas regulatorias tanto de las políticas como de los aspectos jurídicos que condicionan el tratamiento de dichos recursos. 
dados por Nación, lo que beneficia a ciertas provincias, al tiempo que perjudica a otras, acrecentando así las asimetrías interprovinciales (Gervasoni, 2010, p. 86). Dicha desigual distribución de ingresos tiene consecuencias sociales, económicas y políticas. Según argumentan diversos autores (Hidalgo, 2009; Mansilla y Burgos Zeballos, 2009), las regalías profundizan la desigualdad entre las provincias que poseen yacimientos y las que no. Lo que a su vez resultaría negativo para la democracia, ya que, como afirma Gervasoni $(2010$, p. 86) "allí donde el Estado cuenta con acceso a generosos recursos fiscales que no provienen de los impuestos sino de la apropiación de una renta extraordinaria de recursos naturales (...), los gobernantes logran fácilmente subyugar a la sociedad".

La modalidad que asume el sistema de transferencias fiscales, incluidas las regalías, tiene consecuencias en la autonomía política y la dependencia económica de las provincias. Ello en la medida en que, como afirma Leiras (2013), al ser las provincias débiles desde el punto de vista financiero 9 y fuertes en el plano político son económicamente dependientes del Estado nacional y políticamente autónomas del mismo. Como consecuencia, esa dependencia económica puede llevar a las provincias a intercambiar su poder político (capacidad de movilización, maquinaria electoral, influencia sobre legisladores nacionales de la provincia, etc.), a cambio de recursos económicos. Puede orientar la agenda provincial a la voluntad del Estado nacional, aunque sea contraria a los intereses locales, por lo tanto "la orientación general de las políticas varía de acuerdo con las preferencias presidenciales porque los representantes de las provincias ceden su capacidad de influir sobre ellas a cambio de los recursos de puede transferirles el gobierno nacional" (Leiras, 2013, p. 45)

Como afirman Freier y Schaj $(2016$, p. 75) "las acciones tendientes a implementar el fracking varían y no puede observarse una tendencia general unificada". Aquí se esbozaron ciertos factores que, según la literatura analizada, intervienen en la decisión política de impulsar o prohibir el fracking en los sistemas de gobierno federal-descentralizados. La hipótesis que guía el presente trabajo afirma que los factores que inciden en el desarrollo de emprendimientos hidrocarburíferos -en la modalidad del fracking- son la voluntad política del Estado y las características del sistema de transferencias fiscales, en lo que respecta a las regalías hidrocarburíferas. En cuanto al primer factor, la voluntad política del Estado, en línea con la literatura centrada en factores estatales se argumenta que la política energética y su orientación a la explotación de hidrocarburos mediante la técnica del fracking responde a una decisión estatal. En cuanto al segundo factor, las regalías hidrocarburíferas, se argumenta que su incidencia se explica por la particularidad que asume el sistema de regalías en los sistemas de gobierno federal-descentralizados que, como se ha mencionado en el estudio del factor fiscal, condiciona la autonomía política y la independencia económica de los gobiernos subnacionales, limitando la posibilidad de estos de legislar en beneficio de sus propios intereses.

9 Dicha debilidad es consecuencia de la dependencia económica respecto a Nación debido a la concentración de los ingresos tributarios en el nivel federal (Leiras, 2013). 
Ambos factores estarían mutuamente condicionados en la medida en que en ambos el Estado nacional tiene un rol central y capacidad de imponer su agenda. Por un lado, debido a que cuenta con determinados poderes que le permiten que orientar las políticas de acuerdo a su voluntad e interés. Por otro lado, ya que, al ser las provincias dependientes del Estado central, y en la medida en que el mismo es el encargado de distribuir ingresos, las mismas se verían condicionadas a actuar en sintonía con la voluntad del Estado central. A continuación, se estudian dichos factores con el fin de analizar su incidencia en el caso del proyecto de explotación hidrocarburífera en la formación Vaca Muerta.

\section{Proyecto Vaca Muerta: Provincias en encrucijada}

Como se argumentó anteriormente, durante la última década se impulsó el desarrollo de grandes proyectos de explotación de HCNC en el yacimiento Vaca Muerta, la mayor reserva de gas y petróleo del país. El fomento a la explotación de no convencionales como política de Estado generó intensas movilizaciones sociales de rechazo y un aumento en la conflictividad social. Las provincias en las que esta tensión en torno al fracking se desarrolló con mayor impulso fue en las provincias patagónicas, principalmente Rio Negro y Neuquén. Ante ese escenario la respuesta fue, como argumentan ciertos autores, el blindaje a Vaca Muerta por parte del gobierno nacional, el sindicato y dirigentes petroleros para garantizar que no se realizan medidas de fuerza, e impedir la nacionalización de los conflictos locales (Svampa, 2018; Acacio y Wyczykier, 2020).

El impulso dado a Vaca Muerta se enmarca en un contexto de desabastecimiento energético y escasez de hidrocarburos convencionales, que presentaban en 2019 una caída en la producción del 3,6 \% respecto al año anterior, y que se enmarca en una tendencia de caída en la generación de energía, la cual disminuyó entre 2015 y 2019 un 54.5\%, como lo evidencia el Indicador Sintético de Energía ${ }^{10}$ (INDEC, 2019). Lo que implicó la orientación de la política energética hacia la producción de no convencionales. Así, Vaca Muerta aumentó en el 2019 su producción de gas en un 20\%, alcanzando el 63\% de la producción de gas total, y de petróleo (shale) en un 30\%, que pasó de representar el $62 \%$ de la producción nacional aproximadamente (EJES, 2019; Secretaria de Energía, 2019). Esto se produce en mayor medida en dos provincias que comprenden la formación Vaca Muerta: Neuquén y Rio Negro. La provincia de Neuquén representa en la participación nacional de producción de no convencionales el $94 \%$ de petróleo y el $88,8 \%$ de gas, seguida de la provincia de Rio Negro que representa el 6,1\% de petróleo y 4,8\% de gas (Kofman y Crespo, 2018; EJES, 2019). En cuanto a los actores intervinientes, según la Secretaría de Energía, en 2016 el $57,6 \%$ del yacimiento era controlado por tres grandes empresas: YPF $(32,61 \%)$, Total $(13,1 \%)$, y Pampa Energía (12,2\%). Actualmente las empresas con mayor presencia en Vaca Muerta en la extracción de gas son YPF $(31,4 \%)$, Pan American Energy (13,6\%), y Tecpetrol (12\%), y

10 El ISE mide la generación neta de energía, en este caso producido por gas licuado de petróleo (incluido gas butano y propano). El periodo analizado en ambos años corresponde al segundo trimestre. 
en la extracción de petróleo YPF $(40,9 \%)$ y Chevron $(22,1 \%)$. En ambos rubros se observa una disminución de las acciones de YPF en beneficio de compañías privadas, quienes aumentaron su participación (Secretaría de Energía, 2019; EJES 2019).

Con el fin de dar cuenta de los elementos que inciden en el desarrollo del proyecto hidrocarburífero en el yacimiento Vaca Muerta, se analizan a continuación los factores extraídos de la literatura prestando especial atención a aquellos que componen el argumento principal del presente trabajo, a saber: factor estatal y fiscal. En cuanto al primer factor, se retoman brevemente las líneas de acción (políticas, legislaciones, estímulos, etc.) del Estado en torno Vaca Muerta. En lo que respecta al segundo factor, se estudian la recaudación fiscal y las regalías hidrocarburíferas en Argentina y la dependencia de las provincias respecto a las mismas. Además, como se ha mencionado, las características del sistema federal y fiscal puede condicionar la autonomía política, la pluralidad democrática y la independencia económica de las provincias, por lo que se tendrán en cuenta dichas variables. La metodología utilizada es cualitativa y consiste en una triangulación entre datos cuantitativos (provenientes de Comisión Nacional Electoral, INDEC, Ministerio de Trabajo y Producción, Secretaría de Energía, etc.), información cualitativa extraída de la literatura, y diversas fuentes (diarios, debates taquigráficos, normativas, etc.) El recorte temporal comprende los años 2011-2019, con el fin de analizar dos mandatos de gobierno y las transformaciones en la política hidrocarburífera desde la reglamentación del fracking.

En cuanto al factor estatal, como se ha mencionado anteriormente, desde el año 2011 Argentina llevado adelante reformas en el marco jurídico y normativo, sancionando diferentes legislaciones que promueven el desarrollo de la explotación hidrocarburífera. En los dos mandatos de gobierno analizados, la política energética ha mostrado continuidad. La sanción por decreto del Régimen de Soberanía de hidrocarburos (1277/2012), la Ley de Hidrocarburos (27.007/2014), la quita de retenciones a su explotación mediante decreto (349/2016), entre otras medidas, evidencian la orientación del Estado nacional en torno al fracking.

Respecto a la autonomía política y la independencia económica, las cuatro provincias que conforman Vaca Muerta presentan características políticas, sociales y económicas diversas. En cuanto al factor político, podría argumentarse que aquellas provincias que presenten un sistema político más democrático y plural, entendido a este como un sistema con alternancia política, un margen de victoria acotado como consecuencia de elecciones competitivas, y baja criminalización de la protesta y represión, serían más proclives a atender las demandas ciudadanas locales (Favela, 2010), como los reclamos socioambientales y la oposición social hacia el fracking. De las cuatro provincias bajo estudio, se observa que dos de ellas, La Pampa y Neuquén, han sido gobernadas por el mismo partido/frente desde el retorno a la democracia en 1983, es decir, durante diez mandatos consecutivos. Lo que 
da cuenta de una alta permanencia en el poder del partido gobernante, que cuenta con un importante caudal de votos y un margen de victoria ${ }^{11}$ alto, a diferencia de Mendoza y La Pampa que evidencian una mayor alternancia política (ver Cuadro I).

Cuadro I: Permanencia en el poder de partido dominante (1983-2019).

\begin{tabular}{|c|c|c|}
\hline Provincias & Coalición/Partido Gobernante & $\begin{array}{c}\text { Mandatos consecutivos del } \\
\text { Partido Gobernante }\end{array}$ \\
\hline La Pampa & PJ & 10 \\
\hline Mendoza & UCR & 2 \\
\hline Neuquén & FPN (Frente Popular Neuquino) & 10 \\
\hline Rio Negro & JSRN (Juntos Somos Rio Negro) & 2 \\
\hline
\end{tabular}

Fuente: Elaboración propia en base a Atlas Andy Town.

Cuadro II: Resultado en porcentaje de las elecciones provinciales de Gobernador.

\begin{tabular}{|c|c|c|c|c|c|c|}
\cline { 2 - 7 } \multicolumn{1}{c|}{} & \multicolumn{4}{c|}{2015} & \multicolumn{3}{c|}{2019} & Diferencia \\
\hline Provincia & Ganador & Segundo & Diferencia & Ganador & Segundo & 20.88 \\
\hline Mendoza & 48.38 & 41.02 & 7.36 & 51.67 & 36.24 & 15.43 \\
\hline Neuquén & 40.57 & 31.20 & 9.37 & 40.19 & 25.93 & 14.26 \\
\hline Rio Negro & 52.80 & 33.94 & 18.86 & 52.63 & 34.97 & 17.66 \\
\hline
\end{tabular}

Fuente: Elaboración propia en base a datos de Cámara Nacional Electoral y Atlas Andy Town.

En lo que respecta a competencia electoral de las dos elecciones aquí analizadas (ver Cuadro II), en las cuatro provincias se evidencia la predominancia de un partido/frente que resulta ganador con una diferencia superior al 7\%, y que alcanza en las provincias de La Pampa y Rio Negro un margen de victoria superior al 17\%., lo que condiciona su competencia electoral y la pluralidad del mismo. A pesar de que se observan provincias con diferente grado de pluralidad democrática, como es el caso de Mendoza, que cuanta con mayor alternancia política y competencia política-electoral, alta participación social, etc., se observa que, independientemente de las características de su sistema político, las cuatro provincias si bien han legislado e incentivado el fracking en sus territorios también han logrado, en mayor o menor medida, sancionar legislaciones municipales que lo prohíben/ regulan. En ese sentido, en la provincia de La Pampa, a pesar de contar con un grado de democracia que se podría considerar bajo comparado con Mendoza, el diputado opositor, Martín Berhongaray (FREPAM) presentó un proyecto de ley para prohibir el fracking en toda la provincia.

11 Se entiende por margen de victoria a la diferencia entre el partido ganador y el partido que obtiene el segundo lugar. Se argumenta aquí que cuando el margen de victoria electoral sea menor, las elecciones serían más competitivas, la posibilidad de alternancia política sería alta y, por tanto, la pluralidad democrática seria mayor. 
En la misma línea, en Mendoza el gobierno provincial, a pesar de contar con una trayectoria de legislaciones y políticas de protección hídrica y ambiental y en oposición a la demanda de la población que exige su prohibición, posibilitó el fracking en el territorio. Si bien a pesar de ello la provincia ha logrado sancionar legislaciones municipales que lo prohíben/ regulan, algunas de ellas han sido vetadas. Lo mismo se aplica para las dos provincias patagónicas que poseen diferencias en su sistema político y también han sancionado legislaciones de prohibición a nivel local, Neuquén en el municipio Vista Alegre y Rio Negro en Allen, Cinco Saltos, Fernández Oro. En cuanto a su autonomía política, se observa que, durante el mandato presidencial 2011-2015 las cuatro provincias fueron oficialistas, es decir, compartieron el mismo signo político que el Ejecutivo nacional (FPV) ${ }^{12}$,entre ellas Neuquén, la cual fue protagonista en el pacto YPF.SA-Chevron, que como se ha mencionado fue un parteaguas en la política energética e hidrocarburífera argentina. En lo que respecta al período 2015-2019 se observa la misma tendencia, a excepción de la provincia de La Pampa, gobernada por el opositor Carlos Verna (PJ). Estos indicadores, resultan útiles para pensar la autonomía política provincial, en la medida en que aquellas provincias con gobiernos del mismo signo político que el ejecutivo nacional son menos proclives a posicionarse en contra, mientras que los partidos de la oposición suelen tener mayores incentivos para denunciar al Ejecutivo nacional y diferenciarse electoralmente impulsando reformas políticas y legislativas que cuenten con amplia aceptación popular (Murillo 2009, citado en Mangini, 2015, p. 24). Como se evidencia en el caso de La Pampa, donde el diputado Berhongaray (FREPAM) opositor al gobierno provincial presento un proyecto de ley (220/2018) para prohibir el fracking. Aquí se ha observado que las cuatro provincias que comprenden el yacimiento Vaca Muerta se han posicionado a favor del fracking, y las cuatro han compartido el mismo signo/partido político que el Ejecutivo nacional.

\section{Cuadro III: Estructura socioeconómica}

\begin{tabular}{|c|c|c|c|c|c|c|c|c|}
\hline & \multirow{3}{*}{$\begin{array}{l}\text { Pobla- } \\
\text { ción } \\
(2010)\end{array}$} & \multirow{3}{*}{$\begin{array}{c}\text { PBG } \\
\text { (total } \\
\text { nacional) }\end{array}$} & \multicolumn{3}{|c|}{ Empleo (en miles) } & \multicolumn{3}{|c|}{ Hidrocarburos: petróleo y gas } \\
\hline & & & \multirow{2}{*}{$\frac{\text { Público }}{2017}$} & \multicolumn{2}{|c|}{ Privado } & \multirow{2}{*}{$\begin{array}{c}\text { Empresas } \\
2017\end{array}$} & \multicolumn{2}{|c|}{ Empleo $^{13}$} \\
\hline & & & & 2017 & 2019 & & 2016 & 2017 \\
\hline La Pampa & 349.299 & 0.9 & 26.5 & 37.7 & 36.5 & 18 & 607 & 604 \\
\hline Mendoza & 1.885 .551 & 4.2 & 131.5 & 240.2 & 249.8 & 69 & 4820 & 4922 \\
\hline Neuquén & 628.897 & 2.6 & 64.2 & 107.9 & 121.1 & 183 & 2635 & 2759 \\
\hline Rio Negro & 708.799 & 1.3 & 63.5 & 101.3 & 110.1 & 67 & 2331 & 1936 \\
\hline
\end{tabular}

Fuente: Elaboración propia en base a datos del INDEC y Ministerio de Producción y Trabajo.

12 Si bien Neuquén fue gobernada por el partido Movimiento Popular Neuquino, su gobernador Jorge Sapag fue aliado del Ejecutivo nacional. Los restantes gobernadores Oscar Jorge en La Pampa, Francisco Peréz en Mendoza y Carlos Soria en Rio Negro, pertenecían a la alianza oficialista PJ (Partido Justicialista)-FPV (Frente Para la Victoria). 13 Para el caso de Mendoza y La Pampa el indicador tomado para analizar empleo petróleo corresponde al total empleado en minería y petróleo ya que no se disponen de datos discriminados. 
En cuanto a su estructura económica, productiva y fiscal, la misma presenta ciertas diferencias entre provincias. Sus características sociodemográficas y laborales (ver Cuadro III), muestran que hay provincias que presentan una elevada cantidad de empleos públicos, como es el caso Neuquén y Mendoza, lo que puede explicarse por, según afirma Giuliani (2017) la baja creación de empleo que produce el fracking que suele ser respaldado por el Estado de la provincia mediante empleo público. Respecto al sector privado se observa que tanto allí como en el sector hidrocarburífero no se evidencia un importante crecimiento, a pesar del desarrollo del proyecto Vaca Muerta. Respecto al grado de desarrollo y diversificación de su estructura económica y productiva, se considerará desarrollada a las provincias que posean un porcentaje de PBG alto, un componente alto de productos industriales en sus exportaciones, (y su empleo público sea menor al privado), y diversificada, a aquellas cuya exportación y producción (representada en el PBG) y que se componga de diferentes productos (de origen agropecuario, industrial, energía, etc.).

La provincia de Mendoza presenta un sistema económico con mayor diversificación, siendo una de las provincias con más desarrollo productivo e industrial, y mayor participación de su Producto Bruto Geográfico (PBG) en el total nacional (ver Cuadro III). Su exportación se compone en un $66 \%$ de productos de origen agropecuario (MOA, ) en un 18\% de productos de origen industrial (MOI) y un 5\% de energía y combustible (Ministerio de Hacienda, 2019). Las provincias de La Pampa y Rio Negro en cambio, presentan una menor diversificación y desarrollo. SU PBG es el que posee menor representación en el total nacional y su exportación se caracteriza por la presencia en un $70 \%$ de productos primarios, seguidos de productos MOA y, en menor medida, de energía y combustibles. Por su parte, Neuquén presenta una estructura económica caracterizada por la predominancia de energía y combustibles, siendo el principal bien exportable, seguido de productos industriales (MOI) y agropecuarios (MOA). Así, se evidencia que Mendoza, y en menor medida Neuquén, presentan una estructura económica más desarrollada y diversificada que La Pampa y Rio Negro.

\section{Cuadro IV: Transferencias fiscales y regalías hidrocarburíferas}

\begin{tabular}{|l|l|l|l|l|l|l|l|l|}
\cline { 2 - 8 } \multicolumn{1}{c|}{} & \multicolumn{3}{c|}{ Ingresos tributarios total \% } & \multicolumn{4}{c|}{ Regalías Hidrocarburíferas } \\
\cline { 2 - 8 } \multicolumn{1}{c|}{} & Nación & \multicolumn{2}{c|}{ Provincia } & Regalía & \multicolumn{2}{c|}{ Petróleo } & \multicolumn{2}{c|}{ Gas } \\
\cline { 2 - 8 } \multicolumn{1}{c|}{ Nación } & & & & 2017 & $\mathbf{2 0 1 9}$ & $\mathbf{2 0 1 7}$ & $\mathbf{2 0 1 9}$ \\
\hline La Pampa & 61,2 & 38,8 & 3,2 & 1.977 .582 & 1.971 .344 & 423.805 & 351.476 \\
\hline Mendoza & 50,6 & 49,4 & 6,8 & 12.275 .627 & 14.263 .941 & 18.465 .735 & 36.793 .939 \\
\hline Neuquén & 28,3 & 71,7 & 18,9 & 19.882 .453 & 27.198 .028 & 454.583 .541 & 1.689 .395 .888 \\
\hline Rio Negro & 23,7 & 11,0 & 27,7 & 6.555 .290 & 5.521 .116 & 39.323 .919 & 132.343 .118 \\
\hline
\end{tabular}

Fuente: Elaboración propia en base a datos de Secretaria de Energía. 
En cuanto al factor regalías, como se evidencia en el Cuadro IV, tanto en las provincias como en el Estado Nacional, la distribución del monto recibido en concepto de regalías aumentó considerablemente entre los años analizados (correspondientes al mes de Julio), principalmente en la provincia de Neuquén, en la que el incremento fue aún mayor.

Como puede observarse, las regalías petroleras son superiores a las gasíferas, siendo las provincias de Neuquén y Mendoza las más beneficiadas, con un importante incremento en el último año. Ello, a diferencia de La Pampa y Rio Negro cuyas regalías petroleras tienden a ser menores. En cuanto a las regalías gasíferas, se observa un progresivo aumento entre los años 2015-2019 en todas las provincias y el Estado Nacional, con excepción de La Pampa. Neuquén y Rio Negro son las provincias que presentan un crecimiento significativamente mayor. Lo que se explica, en parte, por el incremento en la producción no convencional en ambas provincias, la cual en Neuquén fue del $87,7 \%$ de petróleo y $56,0 \%$ de gas, y Rio Negro fue de $38 \%$ de gas y $4,6 \%$ de petróleo (Secretaria de Energía, 2019). A su vez, en ambas provincias las regalías representan en los ingresos percibidos un alto porcentaje, lo que le implicaría una menor dependencia del Estado Nacional, a diferencia de las restantes provincias.

Además de las regalías, se observa que hay provincias que tienden a menor capacidad de recaudación propia y dependen de las transferencias fiscales del Estado nacional, como es el caso de La Pampa cuyos ingresos provinciales totales se compone en el 61,2\% de transferencias, y es de las provincias analizadas la que menor regalías recibe. El incremento significativo del ingreso que reciben las provincias en concepto de regalías como consecuencia del boom de no convencionales en las provincias, como se ha observado, incidiría en el territorio que conforma el yacimiento Vaca Muerta ("reterritorialización") con transformaciones en el plano social, político y económico local.

Como ha podido observarse, en lo que respecta al factor estatal y jurídico, el Estado en los últimos años llevo adelante transformaciones en el marco legal/jurídico con garantías y beneficios que contribuyeron al desarrollo de explotación de HCNC por capitales privados, en detrimento de empresas nacionales, como lo evidencia la menor participación de YPF en Vaca Muerta. En cuanto al factor de territorialización y de transferencias fiscales de regalías hidrocarburíferas, se evidencia que el aumento en el monto de las mismas puede condicionar a aquellas provincias que poseen una estructura económica orientada a productos de origen agropecuario o industrial, por las transformaciones ambientales que ocasiona el fracking y por la alta rentabilidad que generan sus regalías, las cuales además pueden transformar su sistema político en la medida en que, como afirma Gervasoni (2010), la expropiación de una renta extraordinaria que dota de recursos a los gobernadores puede resultar negativo para la sociedad y la democracia en la provincia. 


\section{Reflexiones finales}

El presente trabajo se orientó a indagar sobre los factores que inciden en el desarrollo de proyectos de explotación de no convencionales, a través del análisis de la literatura abocada al fracking, prestando especial atención a la incidencia del Estado y las regalías hidrocarburíferas.

Como se ha analizado, el Estado asumió desde la década de los noventa hasta la actualidad el rol de árbitro y articulador de la política energética e hidrocarburífera en el país. Ello mediante modificaciones en el marco jurídico y la implementación de políicas públicas que favorecen a los capitales privados transnacionales, entre las que se destacan el Régimen de Promoción de las Inversiones para la Explotación de Hidrocarburos, la Ley de Soberanía Hidrocarburífera que posibilita el uso de nuevas tecnologías y modalidades de explotación (entre ellas el fracking), el acuerdo YPF-Chevron-Neuquén, la baja de retenciones, entre otras. Así antes que la apuesta por una transición hacia energías limpias y renovables se evidencia que los distintos gobiernos aquí estudiados, han llevado adelante una política energética destinada a profundizar la actual matriz energética dependiente de combustibles fósiles. Asimismo, estas diferentes medidas no fueron acompañadas por normativas ambientales nacionales y provinciales que regulen la técnica del fracking, además de excluir instancias o mecanismos de participación social que democraticen las decisiones tomadas que afectan a la población local.

En cuanto a las regalías, se ha evidenciado el alto porcentaje que las mismas representan en los ingresos provinciales, en detrimento de la autonomía políticas y las actividades económicas locales prexistentes, lo que puede resultar negativo para el desarrollo local en la medida en que, los gobiernos provinciales y locales se orienten al fracking y la explotación de HCNC por su rentabilidad financiera. En suma, se evidencia la necesidad de políticas públicas planificadas y coordinadas entre los tres niveles de gobierno que orienten los recursos provenientes de las regalías hacia la implementación de políticas de desarrollo local sustentable.

\section{Bibliografía}

Acacio, J. (octubre de 2018). Fracking e hidrocarburos no convencionales en la Provincia de Neuquén: un acercamiento al conflicto desde la perspectiva de los actores. En Jornadas Platenses de Geografía y XX Jornadas de Investigación y de Enseñanza en Geografía. La Plata, Argentina: Universidad Nacional de La Plata

Acacio, J., y Wyczykier G. (2020). Expectativas públicas y conflictos sociales en torno a los hidrocarburos no convencionales en Argentina: algunos apuntes sobre Vaca Muerta. Izquierdas (49), 457-477. doi: 0718-5049

D'Elía, D., y Ochandio. R. (2014). ¿Qué es la o fractura hidráulica o fracking? ¿̇Es una técnica experimental? ¿Cuáles son sus etapas y características? ¿Qué son los hidrocarburos no convencionales? En Colectivo Voces de Alerta (Ed.), 20 mitos y realidades del fracking, (pp. 17-28). Buenos Aires, Argentina: Chico Mendes.

D' Elía, D., y Observatorio Petrolero Sur. (2014). ¿2Por qué la apuesta a la explotación al gas no convencional en Argentina? Empresas y gobierno afirman 
que la Argentina cuenta con inmensos recursos no convencionales y una de las reservas más importantes del mundo, ¿esto está probado? En Colectivo Voces de Alerta (Ed.), 20 mitos y realidades del fracking (pp. 49-62). Buenos Aires, Argentina: Chico Mendes.

EJES (2019). Informe Coyuntura hidrocarburífera. Recuperado de http://ejes.org. ar/InfoJulio.pdf

Favela, M. (2010). Sistema político y protesta social: del autoritarismo a la pluralidad. En I. Bizberg y F. Zapata (Coord.), Los grandes problemas de México, (pp. 101-146). México D.F, México: El Colegio de México.

Fernández, C. (2012). Anunció del proyecto de ley de expropiación de YPF: Discurso de la Presidenta de la Nación. Recuperado de https://www.casarosada.gob.ar/informacion/archivo/25810-anuncio-del-proyecto-de-ley-de-expropiacion-de-ypf-discurso-de-la-presidenta-de-la-nacion

Foro Ambiental. (2017). En el corazón de la provincia de Buenos Aires también le dicen no al fracking. Recuperado de https://www.foroambiental.net/corazon-la-provincia-buenos-aires-tambien-le-dicen-no-al-fracking/

Freier, A., y Schaj, G. (2016) La fractura hidráulica en Argentina: los cambios en el concepto de territorialidad y la emergencia de nuevos regímenes de soberanía. Revista Enfoques, (25), 59-81. doi: 0718-0241.

García Delgado, D. (2014). Recursos naturales estratégicos, el rumbo a seguir. Revista Estado y Políticas Públicas, (3), 13-15. doi: 2310-550.

García Zanotti, G., Kofman, M., y López Crespo, F. (2016). Informe Económico: Transferencias al sector hidrocarburífero en Argentina. EJES. Recuperado de http://ejes.org.ar/InformeTransferencias.pdf

Gervasoni, C. (2010) Democracia, autoritarismo e hibrides en las provincias argentinas: La medición y causa de los regímenes subnacionales. Journal of Democracy en Español, 75-93. Recuperado de http://historiapolitica.com/ datos/biblioteca/gervasoni.pdf

Giuliani, A. M. (2017). La explotación de hidrocarburos en Argentina. En el marco de la gobernanza. Revista Administración Pública y Sociedad, (3), 49-61. Recuperado de https://revistas.unc.edu.ar/index.php/APyS/article/view/16813

Gutiérrez Ríos, F. (2014). Violencia física y simbólica en el contexto extractivista petrolero en la Argentina. Anuari del conflicte social, 37-57. Recuperado de http://revistes.ub.edu/index.php/ACS/article/view/12274/15027

Hidalgo, E. (2009). Competencia de la Nación y las provincias en la explotación de hidrocarburos en Argentina. Realidad Económica, (241), 66-93.

INDEC. (2019). Indicadores del sector energético. Recuperado de https://www.indec.gob.ar/uploads/informesdeprensa/indicadores_energeticos_09_19D9B9C124A9.pdf

Kofman, M., y López Crespo, F. (2018) Úselo y tírelo. Empleo petrolero en la Argentina no convencional. Ejes. Recuperado de http://www.opsur.org.ar/blog/ wp-content/uploads/2018/06/EJES-\%C3\%9Aselo-y-t\%C3\%ADrelo.-Empleo-petrolero-en-la-Argentina-no-convencional.pdf

La Política Online. (marzo de 2013). Por orden de Cristina, vetaron en Río Negro una ordenanza que prohibía el fracking. Recuperado de https://www.lapoliticaonline.com/nota/nota-89034/

Leiras, M. (2013). Las contradicciones aparentes del federalismo argentino y sus consecuencias políticas y sociales. En C. Acuña (Ed.), Cuanto importan las instituciones (pp.209-248). Buenos Aires, Argentina: Siglo XXI.

Macri, M. (2017). Palabras del presidente Mauricio Macri en el anuncio de acuerdos con la provincia de Neuquén, empresas petroleras y sindicatos del sector para el desarrollo del Yacimiento Vaca Muerta. Disponible en https:// www.casarosada.gob.ar/informacion/discursos/38328-palabras-del-presidente-mauricio-macri-en-el-anuncio-de-acuerdos-con-la-provincia-de-neuquen-empresas-petroleras-y-sindicatos-del-sector-para-el-desarrollo-del-yacimiento-vaca-muerta-salon-blanco-de-la-casa-rosada

Mangini, M. (2015). Economía política el cambio institucional en la política minera de las provincias argentinas (Tesis de magister). Buenos Aires, Argentina: Universidad de Torcuato Di Tella.

Mansilla, D., y Burgos Zeballos, M. (2009). Las regalías hidrocarburíferas en la desigualdad fiscal provincial. Realidad Económica (246), 37-59. doi: 0325-1926

Ministerio de Trabajo. (2019). Informes Provinciales. Disponible en http:// 
WwW.trabajo.gob.ar/estadisticas/informesprovinciales/index.asp Ministerio de Hacienda. (2019). Informes Productivos Provinciales. Disponible en: https://www.argentina.gob.ar/economia/politicaeconomica/microeconomica/informesproductivos\#regionales

Morina, O., y Cacace. G. (2014). De la privatización total a la reestatización parcial de YPF y las concesiones al capital extranjero. Revista del Departamento de Ciencias Sociales (3), 48-68. Recuperado de http://www.redsocialesunlu. net/wp-content/uploads/2017/09/REDSOC022-02-GEOGRAF\%C3\%8DA-MORINA-CACACE-P\%C3\%81G.-03-18.pdf

Observatorio Petrolero Sur. (2011). Shale Gas: hacia la conquista de la nueva frontera extractiva. Recuperado de http://www.opsur.org.ar/blog/2011/07/01/ shale-gas-hacia-la-conquista-de-la-nueva-frontera-extractiva/

Peinado, G., y Saguier. M. (Julio 2014). Minería transnacional y desarrollo en el kirchnerismo. En Joint International Conference Global And Regional Powers In A Changing World. Buenos Aires, Argentina: FLACSO-ISA

Peralta, M. E., Abella A. P., y Albareque, J. F. (2005). Tratamiento impositivo y jurídico de las regalías en la Argentina. Pirotecnia, 62-97. Recuperado de http:// biblioteca.iapg.org.ar/ArchivosAdjuntos/Petrotecnia/2005-4/Tratamiento.pdf

Recalde, M., Boville, D.H., y Girardin, L.O. (2015). Limitaciones para el desarrollo de energías renovables en Argentina. Revista Problemas del Desarrollo (46), 89-115. Recuperado de http://www.scielo.org.mx/pdf/prode/v46n 183/03017036-prode-46-183-00089.pdf

Rodríguez Garavito, C. (2012). Etnicidad.gov, Los recursos naturales, los pueblos indígenas y el derecho a la consulta previa en los campos sociales minados. Bogotá, Colombia: Dejusticia.

Rodríguez Garavito, C. (2016). Extractivismo versus derechos humanos. Buenos Aires, Argentina: Siglo Veintiuno Editores.

Secretaría de Energía. (2019). Balance de gestión en energía, 2016-2019. Disponible en: http://www.energia.gob.ar/contenidos/archivos/Reorganizacion/ sintesis_balance/2019-12-09_Balance_de_Gestion_en_Energia_2016-2019_final_y_anexo_pub_.pdf

Svampa $\bar{M}$. E. (2018). Frankenstein. Vaca Muerta, entre la inviabilidad ambiental y el pluriblindaje. El cohete a la luna. Recuperado de https://www.elcohetealaluna.com/a-mas-extractivismo-menos-democracia.

Svampa, M.E., y Viale. E. (2014). Una vuelta de tuerca al extractivismo: el fracking como el nuevo "El Dorado". En M. E, Svampa y E. Viale (Ed.). Mal desarrollo. La argentina del extractivismo y el despojo (pp.299-352). Buenos Aires, Argentina: Katz.

Tapia, M. (2014). Consideraciones sobre el sistema de redistribución de las regalías mineras. La complejidad del desarrollo para Antofagasta de la Sierra (Catamarca, Argentina) (2004-2012). Estado y Políticas Públicas, (3), 62-78.

Vargas Suárez, R. (2015). Reforma energética. De servicio público a modelo de negocios. Política y Cultura, (43), 125-145. doi: 0188-7742.

Vergara, R., Barreto Nieto, C., y Prieto Bustos, W. (2012). Medición de la eficiencia en el uso de las regalías petroleras: una aplicación del análisis envolvente de datos. Finanzas y Política Económica (4), 13-32. Recuperado de https://dialnet.unirioja.es/descarga/articulo/4246510.pdf 